\title{
Study of Parameters of Acoustic and Thermal Comfort of a House Built with Green Bricks
}

\author{
A. O. Esteves ${ }^{1,2}$ and T. M. Souza ${ }^{1,2}$ \\ ${ }^{1}$ Department of Electrical Engineering \\ UNESP \\ Campus of Guaratinguetá - Av. Ariberto Pereira da Cunha, 333 - Pedregulho (Brazil) \\ ${ }^{2}$ Renewable Energies Center - UNESP (www.feg.unesp.br/energiasrenovaveis)
}

Phone/Fax number:+55 012 31232777, e-mail: es.amanda@gmail.com, teofilo@feg.unesp.br

\begin{abstract}
The proposed work consists in study and check the temperature, humidity and acoustics of a home built with green bricks, made of soil, cement and water, in Guaratinguetá Brazil, to compare and show benefits in the aspects of acustics, thermal, energy and residual, compared to conventional buildings. Is also made the calculus of the amount of such bricks.

This kind of construction is typical of tropical regions, like Brazil, because of your thermal benefits.

The instrumentation of the house was made using temperature meters, moisture meter, sound level meter, anemometer and density meter solar power. Was collected the temperatures, moisture content, wind speed and solar radiation at different periods.

On a day with sunlight $130,4 \mathrm{~W} / \mathrm{m}^{2}$, the outside temperature was $24,4^{\circ} \mathrm{C}$ and internal temperature was $26,6^{\circ} \mathrm{C}$ and the wind speed was $1,1 \mathrm{~m} / \mathrm{s}$. Already on days with higher solar radiation $891 \mathrm{~W} / \mathrm{m}^{2}$, the outside temperature was $30,8^{\circ} \mathrm{C}$ and the internal temperature was $24,4^{\circ} \mathrm{C}$, and the wind speed was 0,7 $\mathrm{m} / \mathrm{s}$.

The results was positives, the green bricks provided the benefits mentioned above, showing that this type of construction can benefit society and the environment, encouraging their use.
\end{abstract}

\section{Key words}

Ecological Bricks, Green House, Energy Efficiency, Soil Cement.

\section{Introduction}

Currently, to minimize the environmental impacts caused by construction, professionals in this area seek using materials and resources that cause less environmental degradation. The eco-brick, made of cement, water and soil, is the most appropriate material and is being used for this purpose. It has several benefits compared to conventional brick, such as thermal stability, combat the humidity, acoustic properties and ease of electrical installations and hydraulic housing, all these benefits are due to these bricks have holes, that create tubes inside the walls. Also, these bricks provide economy in construction, less material waste, structural efficiency and reduction of power consumption. In addition, their raw material, soil, is an abundant material on the planet. Another very important aspect of this brick is that it doesn't need to be burned in its finalization, as is done in ceramic bricks.

This type of brick fits into the sustainable tripod, which consists of the features: social, economical and environmental. They spends $1 / 4$ of energy in its production process compared to ceramic bricks, and doesn't emit any type of waste to the environment, also the cost of the construction will be between 40 to $50 \%$ cheaper if you use the eco-bricks.

These bricks are used since the first decade of the 20th century in the United States and the pioneering research on this material are of 1935, made along the PCA Portland Cement Association. Starting in 1960, the soilcement began to have several scientific studies and began to dissemination in Brazil by IPT - Technological Research Institute of São Paulo and the ABCP - Brazilian Association of Portland Cement.

Tropical countries are great places for green buildings due to high incidence of solar radiation, heat and humidity. The benefits of green bricks can be clearly seen in the aspect of maintaining a pleasant temperature inside the building and avoid moisture on the walls of the house.

Knowing these benefits, and having a construction already completed on the campus of UNESP Guaratinguetá (Fig 1), was done this project with the objective of studying, perform measurements and analyze the parameters of acoustic and thermal comfort of this construction, as well as calculate the number of bricks that will be used in buildings. 


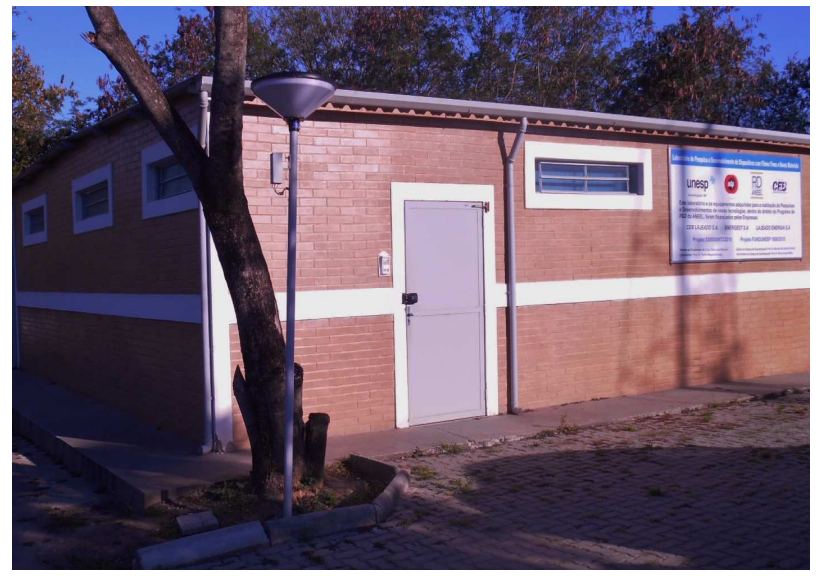

Fig. 1 House built with bricks soil cement

\section{Objectives}

The present project aims to study, check and analyze the internal and external temperature, the humidity and the internal and external acoustic of a house built with green bricks and also compare with constructions made with conventional bricks and show benefits. Is also made the calculation of the quantity of bricks that will be used in buildings.

\section{Materials and Methodology}

All the resources for the implementation of this project are located in the Renewable Energies Center, situated at the Faculty of Engineering of Guaratingueta - UNESP. They are:

- A house of $102 \mathrm{~m}^{2}$, consists of kitchen, laundry area and 4 convenient (Fig. 1).

- Temperature meter;

- Humidity meter;

- Density meter solar power;

- Anemometer;

Instrumentation was made of the house located at the Faculdade de Engenharia de Guaratinguetá, that was building with ecological bricks, using the meters mentioned above, in order to collect temperature inside and outside the home, wind speed, solar radiation intensity and humidity on different days in order to comparing the results obtained with constructions made of conventional bricks.

These data were collected on different days of the year, as well as periods with more or less outside noise, to compare the results obtained in different climates and weather, and prove that in hot days as cold days, the house made of green bricks has a pleasant indoor temperature, and show that there is a good sound insulation of the house.
For the design of ecological bricks, information is needed as length of walls, ceilings, size and number of windows and doors.

Its calculated a brick house with a bedroom, kitchen, living room and a bathroom (Fig. 2) to demonstrate how is done this calculation.

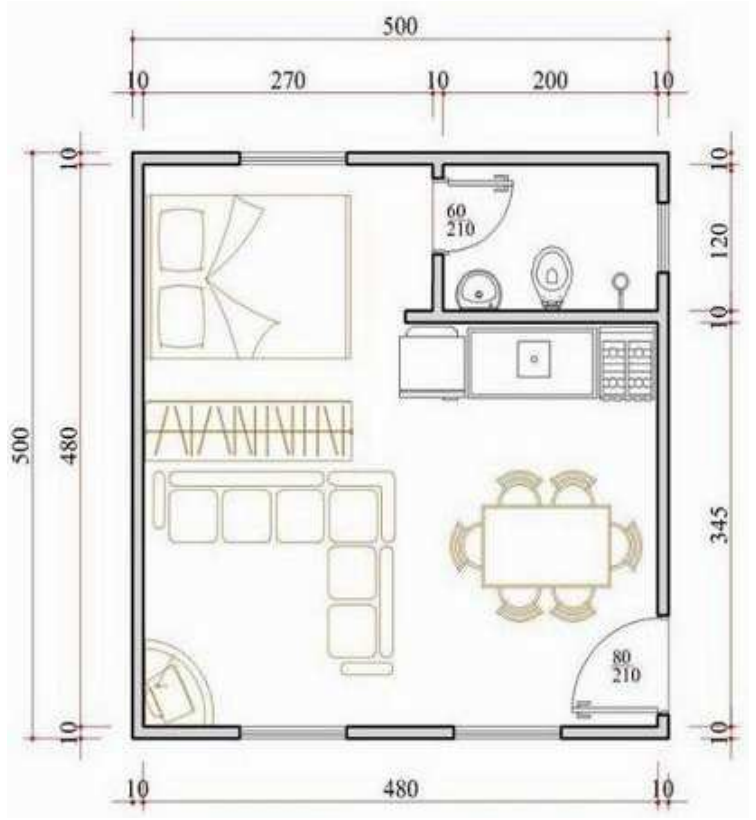

Fig. 2 - Floorplan of a house.

There are three size types of ecological bricks that we use: $30 \times 15 \times 7,5 \mathrm{~cm} ; 25 \times 12,5 \times 7,5 \mathrm{~cm} ; 25 \times 12,5 \times$ $6,25 \mathrm{~cm}$.

It was used the brick $30 \times 15 \times 7.5 \mathrm{~cm}$ for this calculation.

First was necessary to verify the length of the internal and external walls (L) and the right foot (Rf), to latter found the area of the walls (A) of the construction (1).

$$
\mathrm{A}=\mathrm{L} \cdot \mathrm{Rf}
$$

It was calculate the area of the doors and windows of the house (area $=$ length $\mathrm{x}$ height), then, it was subtract the sum of the windows' and doors' area of the area of the walls that was previously found, because, in the windows' and doors' area doesn't have bricks, so it is necessary to subtract.

Found this, multiplies the value by:

A. 45 , if the choose brick was the $30 \times 15 \times 7,5 \mathrm{~cm}$;

B. 53 , if the choose brick was the $25 \times 12,5 \times 7,5 \mathrm{~cm}$;

C. 65 , if the choose brick was the $25 \times 12,5 \times 6,25$ $\mathrm{cm}$;

which is the number of bricks per $\mathrm{m}^{2}$. Made this calculation, it was found the number of bricks (Fig 3).

To find the number of half-bricks top (Fig. 4) (intersection of walls), it was counted the number of these intersections, and then multiply for the right foot and divide by:

D. 0,075 , if the choose brick was the $30 \times 15 \times 7,5$ $\mathrm{cm}$;

E. 0,0625 , if the choose brick was the $25 \times 12,5 \times$ $6,25 \mathrm{~cm}$; 
$\mathrm{cm}$;

To find the number of half-bricks side windows and doors, it was necessary multiply the number of windows by its respective height and multiply the number of doors by their respective height too. Found these values, they were added and then, divided by:

G. 0,075 , if the choose brick was the $30 \times 15 \times 7,5$ $\mathrm{cm}$;

H. 0,0625 , if the choose brick was the $25 \times 12,5 \times$ $6,25 \mathrm{~cm}$;

I. 0,075 , if the choose brick was the $25 \times 12,5 \times 7,5$ $\mathrm{cm}$;

And finally, it was calculated the number of bricks channels, which are used in the upper and lower parts of windows and walls and tops of doors.

It was found the length of all the walls (L), then, multiplied by two, because, will be use this kind of brick on top and bottom of the walls. Then, the area of all windows plus $60 \mathrm{~cm}$ (that is a length of bricks channels that we should pass the length of the window or door, to provide a better resistance, so, $30 \mathrm{~cm}$ for the left and 30 $\mathrm{cm}$ for the right) are multiplied by two too, because will be use this kind of brick on top and bottom of the windows. Then, the area of all doors plus $60 \mathrm{~cm}$, are multiplied by one, because there is only one row top brick channels. These values that were found were multiplied by 3.3 , which is the number of channels per meter. Finally, doing all these calculations, it was found the number of bricks channels (Fig. 5).

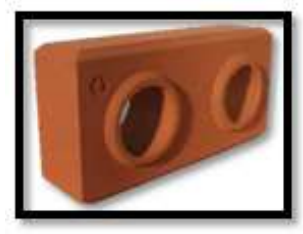

Fig. 3 Ecological Brick

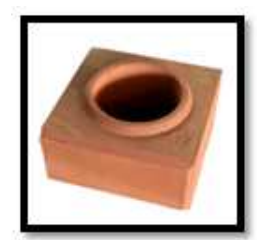

Fig. 4 Ecological Half - Brick

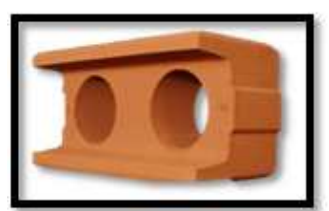

Fig. 5 Ecological Brick Channel

\section{Results}

Through instrumentation made with the house located at the UNESP's campus of Guaratinguetá, various results were obtained, as can be seen in Table 1 .
Table 1 - Typical information collected in the house built with green bricks

\begin{tabular}{|l|c|c|c|}
\hline & DAY 1 & DAY 2 & DAY 3 \\
\hline Solar Radiation $\left(\mathrm{W} / \mathrm{m}^{2}\right)$ & 891 & 130,4 & 12,2 \\
\hline Wind Speed $(\mathrm{m} / \mathrm{s})$ & 0,7 & 1,1 & 1,4 \\
\hline Outside temperature $\left({ }^{\circ} \mathrm{C}\right)$ & 30,8 & 26,6 & 22,5 \\
\hline Internal Temperature $\left({ }^{\circ} \mathrm{C}\right)$ & 24,2 & 24,4 & 24,6 \\
\hline Humidity & $54 \%$ & $50 \%$ & $60 \%$ \\
\hline
\end{tabular}

The day 1, was a spring day with a few clouds and a large solar radiation. The outside temperature of the house was elevated, but inside the construction we could saw that the temperature was around $24^{\circ} \mathrm{C}$.

The day 2 was a spring day with a lot of clouds and a small solar radiation. The outside temperature was little more elevated then the internal temperature, that also was around $24{ }^{\circ} \mathrm{C}$.

The day 3 was spring day after rain, with a lot of clouds and a very small solar radiation. The outside temperatura was less elevated the the internal temperatura, that also was around $24^{\circ} \mathrm{C}$.

\section{Temperature x Days}

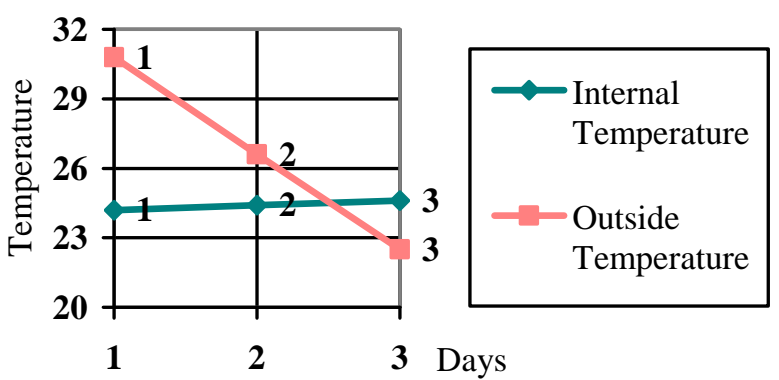

Graphic 1. - Analysis of internal and outsid temperature of a construction made of green bricks.

Since the buildying was built, it never had a problem with humidity.

Could saw too, that the outside noise, like the noise of passing cars, is not heard from inside the house made of green bricks.

It was made the calculation of the number of bricks of a house located at the UNESP's campus of Guaratinguetá (Fig. 2).

To find the number of bricks, was used the method explained above, and for this, the following data was used in the house:

J. Windows' Size $(1,0 \times 1,0) \mathrm{m}$;

K. Doors' Size $(0,8 \times 2,1) \mathrm{m}$;

L. Right foot $(3 \mathrm{~m})$;

M. Length of the internal and outside walls $(23,4 \mathrm{~m})$;

N. Brick used $(30 \times 15 \times 7,5) \mathrm{cm}$;

Doing the calculation, was found the values shown in Table 2. 
Table 2 - Number of house bricks in Figure 2

\begin{tabular}{|l|c|}
\hline Bricks & 2828 \\
\hline Half Bricks & 340 \\
\hline Trenches & 206 \\
\hline Total Bricks & 3374 \\
\hline
\end{tabular}

\section{Conclusion}

With these results, it was verified that the buildings made of green bricks actually provide many benefits, such as thermal and acoustic comfort, reduced spending and lower environmental impact.

Was posible to verify that in all analyzes previously exposed, the internal temperature of the construction stayed about $24^{\circ} \mathrm{C}$, that is value that provides a comfort ambient.

The buildying didn't have problems with humilty, because these ecological bricks avoid this kind of problem, because they have the holes that allow the steam pass through the holes and don't accumulate at the walls.

In addition, these holes inside of the green bricks, provide too, sound insulation and the comfort of internal temperature of the house, because, these holes create tubes inside the wall, and, the air is a good thermal insulator.

Knowing these informations, one can assume that a house with ecological bricks built provide a cost saving with acoustic insulation and temperature on the walls, plus the time and money due to easy fitting and less wasted material, as well as lower energy expenditure, because the brick don't have to be heated to cure.

Thus, can conclude that this type of brick is a sustainable product, which must be used worldwide for the impacts of buildings been much smaller in the environment, as well as reduce consumption of energy and materials.

\section{References}

[1] ABNT, 1994a. Brazilian Standard NBR 10836 e SoilCement Bricks: Determination of Compressive Strength and Water Absorption. Brazilian Association of Technical Standards.

[2] Mbnta, A. (1989,,). Durability of soil-cement for building pur- poses. Into'national Conference on th mortcl strateg for Tech DevelopmenL Book of abstracts, No. 77, 1989, Aug

[3] Portland Cement AssoclaUon, PCA (1956). Soil Cement Construction Handbook, PCA, Cldcago III 1956.

[4] Miranda, L.A., Alvarenga, R.C.S.S., Junior, P.C.M.P., Junior, E.D.P., Carvalho, C.A.B.,Fassoni, D.P., Couto, L.G., 2011. Evaluation of grits as the building materials inthe production of soil-cement bricks. Rev. Árvore 35, 1335e1340. 